\title{
Correction to: Sustained social withdrawal behavior and 'difcult' temperament among infants, in relation to maternal afectivity in a low-income area of Kinshasa, Democratic Republic of Congo
}

\author{
Daniel Okitundu-Luwa ${ }^{1}(1)$ Brigitte Imbula Essam ${ }^{2} \cdot$ Marie-Thérèse Sombo Ayanne $^{3} \cdot$ Ally Ndjukendi Omba $^{2}$. \\ Franck Otete Djamba ${ }^{4}$. Tharcisse Kayembe Kalula ${ }^{5}$. Timothée Kamanga Mbuyi ${ }^{6}$. Antoine Guedeney ${ }^{7}$. \\ Espérance Kashala-Abotnes ${ }^{8}$
}

(c) Springer-Verlag GmbH Germany, part of Springer Nature 2021

\section{Correction to: European Child \& Adolescent Psychiatry https://doi.org/10.1007/s00787-021-01873-9}

In the original article, the name of eighth author published incorrectly. The correct name is Antoine Guedeney.

The original article has been corrected.

The original article can be found online at https://doi.org/10.1007/ s00787-021-01873-9.

Daniel Okitundu-Luwa

danielokitundu@hotmail.com; daniel.okitundu@unikin.ac.cd

1 Unités de Neurologie Pédiatrique et de Neuropsychologie, Département de Neurologie, Centre Neuro Psycho Pathologique du Mont-Amba, Faculté de Médecine, Université de Kinshasa, B.P.825, Kinshasa,

Democratic Republic of the Congo

2 Service de Psychiatrie Femme et Enfants, Département de psychiatrie, Centre Neuro Psycho Pathologique du Mont-Amba, Faculté de Médecine, Université de Kinshasa, Kinshasa, Democratic Republic of the Congo

3 Unité de Neuropsychologie, Département de Neurologie, Centre Neuro Psycho Pathologique du Mont-Amba, Faculté de Médecine, Université de Kinshasa, Kinshasa, Democratic Republic of the Congo

4 Médecin Chargé de la Recherche et la Documentation Scientifique à la Fondation pour la Promotion et la Protection de la sante mentale de l'enfant «FOPPROSAME Asbl», Kinshasa, Democratic Republic of the Congo

5 Service de Neurodiagnostic, Département de Neurologie, Centre Neuro Psycho Pathologique du Mont-Amba, Faculté de Médecine, Université de Kinshasa, Kinshasa, Democratic Republic of the Congo

6 Département de Psychologie Clinique, Faculté de Psychologie et Sciences de l'Education Département et, Consultant au Département de Neurologie, Université de Kinshasa, Kinshasa, Democratic Republic of the Congo

7 Service de Psychiatrie de l'enfant et de l'adolescent, Hôpital Bichat, APHP, Paris et Université de Paris, Paris, France

8 Department of Global Public Health and Primary Care, Centre for International Health, University of Bergen, Bergen, Norway 